\title{
WHAT CAN PETROCALCIC LAMINAE TELL US ABOUT SOIL PROCESSES AND PALEOENVIRONMENTS?
}

KURT CRANDALL, Pitzer College

Research Advisor: Colin Robins (Claremont Mckenna, Pitzer, and Scripps Colleges)

\section{INTRODUCTION}

Pedogenic carbonate forms in arid to semi-arid environments when infiltrating soil water evaporates and deposits solutes rather than leaching them through the soil profile. The amount and morphology of carbonate accumulation in soils, along with the overall degree of horizon and profile development, evolve over time (Brock \& Buck 2009), reflecting relative age, and climate and/or geomorphic stability. The term "petrocalcic horizon" describes horizons in which carbonate accumulation has either completely engulfed and/or indurated the horizon, while "calcic horizon" reflects younger relative ages of less-extensive carbonate accumulation without complete horizon cementation (Soil Survey Staff, 2014).

Laminated horizon caps are the defining morphological indicator of the transition from calcic to petrocalcic horizon (Gile et al., 1966; Machette, 1985), but they are not always well described nor adequately understood. Laminae are defined as an internal fabric and are described according to thickness, regularity, and orientation (Bullock et al., 1985; Stoops, 2003). The accepted mode of formation of laminar caps is addressed by a broader model for calcic and petrocalcic horizon development (e.g., Schoeneberger et al., 2012). This progressive horizon development model was developed first as a four-stage model (Gile et al., 1966) including the laminar horizon at stage IV, and later refined to include two additional, later stages (Machette, 1985). However, other authors have shown the need to tailor all or part of this horizon-focused model to fit whole profiles, specific world regions, or to develop new models completely (Brock \& Buck, 2009; Alonzo-Zara \& Tanner, 2010; Robins et al.,
2015).

Internally or between horizons, pedogenic carbonate laminae often exhibit different morphologies, colors, mineral compositions, geochemistries, and architecture (Brock \& Buck, 2009; Levine \& Hendricks, 1990). Most are made of calcite or low-Mg calcite, but some include detrital quartz grains surrounded by cements which suggests dissolution, at least partial void filling by unconsolidated soil or sediment, and recrystallization (Stoops et al., 2010). Some laminae contain authigenic sepiolite and palygorskite clays (Robins et al., 2015; Hudnall et al., 2010, Vanden Huevel, 1966) in aggregates, as individual fibers, and as grain coatings. Moreover, other soil features contain or are surrounded by laminae in carbonate-cemented soils. For example, pisoliths are pointed, concentric, vertically tapering, accretionary structures thought to have formed through infilling of a dissolution void or fractured and eroded surface (Robins et al., 2012). After the void forms, rainfall washes solutes into these open or sand-infilled void spaces, coating grains and these spaces can be filled completely creating a calcified mass (Gile et al., 1966; Machette 1985). Pisoliths are common in petrocalcic soil horizons that are subject to alteration by chemical and mechanical weathering (Arakel, 1982; Robins et al., 2012; Dunham 1969).

Thus, published hypotheses regarding the origin of laterally continuous laminations in calcic and petrocalcic horizons include (1) formation as a cap, (2) formation due to biological processes, (3) dissolution and growth of calcite crystals in pores and cracks, (4) infusion and neoformation of clays, and (5) formation in localized pedogenic structures. 
Hypothesis 1 is the only hypothesis included in the VI Stage model (Machette 1985). More detailed analysis of the occurrence and morphology of laminae within calcic and petrocalcic horizons is needed to test and/ or refine existing models for their genesis, mineralogy, and to address competing hypotheses about their genesis. An important first step in that analysis is the detailed micromorphological and mineralogical and classification of pedogenic laminae.

\section{Objectives and Hypotheses}

Using Mormon Mesa as a case study that may be broadly applicable to other petrocalcic soil and/or paleosol horizons around the world, it is hypothesized that mineralogy, elemental concentrations, and stable isotope geochemistry may vary among laminae of distinct morphologies, colors, or mineralogies, with implications for solution chemistry, and mode and depth of formation.

Thus, the overall goal of this project is to investigate the morphology and mineralogy of the calcic laminae in the petrocalcic horizons, to test and refine existing models for their genesis, especially the VI stage model. Questions explored included: (1) are there any top-bottom indicators in the laminae, (2) do the widely varied colors of laminae correlate with crystal size, detrital grain content, or mineralogy?

\section{METHODS}

\section{Location and Sampling}

The study sites for this project are located in the Mojave Desert at Mormon Mesa and Flat Top Mesa, Nevada, just outside of Mesquite Nevada, about 100 $\mathrm{km}$ northeast of Las Vegas. The formation of the Mormon Mesa soil in Muddy Creek Formation parent materials coincides with the incision of the Muddy Creek and Virgin Rivers in response to the downcutting of the lower Colorado River.

Three informally-named sites with existing exposures of the soil profile and stratigraphic section were described and sampled at Mormon and Flat Top Mesas, NV: (1) Riverside, (2) Flat Top East (FTE), and (3) Flat Top West (FTW). The Riverside exposure occurs in a road cut along an abandoned highway that exposes tall $\sim 5-12 \mathrm{~m}$ soil profiles and stratigraphic sections. The Flat Top East exposure also lies in a short $\sim 100 \mathrm{~m}$ long roadcut, made to assist in installing powerlines in the area. Additionally, the cut extends to edge of the mesa and is about 3-8 $\mathrm{m}$ tall in some locations. By contrast, Flat Top West is a natural, $12 \mathrm{~m}$ vertical exposure along the Mesa's edge and is harder to access than the other locations.

Samples were chosen in a targeted rather than random fashion, by searching the massive horizon for laminae. I limited my search to areas exhibiting large amounts of layers of laminae as to maximize my study. I also tried to find samples and areas that showed laminae in multiple directions, as well as ones that were only going in one direction, in order to sample the most complete range of contexts possible. I also targeted different colors and shapes of laminae for a complete and thorough comparison, using a Munsell Soil Color Book to normalize color descriptions. Samples were photographed in situ in the field and described in detail before collection.

\section{Optical Microscopy}

A Nikon LV100 Universal microscope with an automated motorized stage was used to describe soil mineralogy and micromorphology in thin section. Optical images collected using cross- or planepolarized transmitted light were compared to digital photographs of billets in hand sample (reflected light) to identify different laminae types based on color in the field and in hand sample. The main magnification used was $4 \mathrm{x}$, though 10x was often used to image smaller features. Metrics used to describe samples are based on the soil micromorphology guidelines from Stoop et al. (2003) and Bullock et al. (1985). Metrics included: contact distinctness \& shape; thickness; color; mineralogy; crystal size, and fabric.

Modifications to standard terminology were required for clarity in a number of instances. In particular, Stoops (2003) and Bullock et al. (1985) define shape in a binary classification system as only either parallel or convolute. In this study, a third shape category is added. Shape then varies from straight to wavy to irregular to broken. Wavy can vary anywhere (and is stated) from parallel to wavy. The definition of wavy is $1 / 2$ wavelength $>$ amplitude. Irregular is defined as 


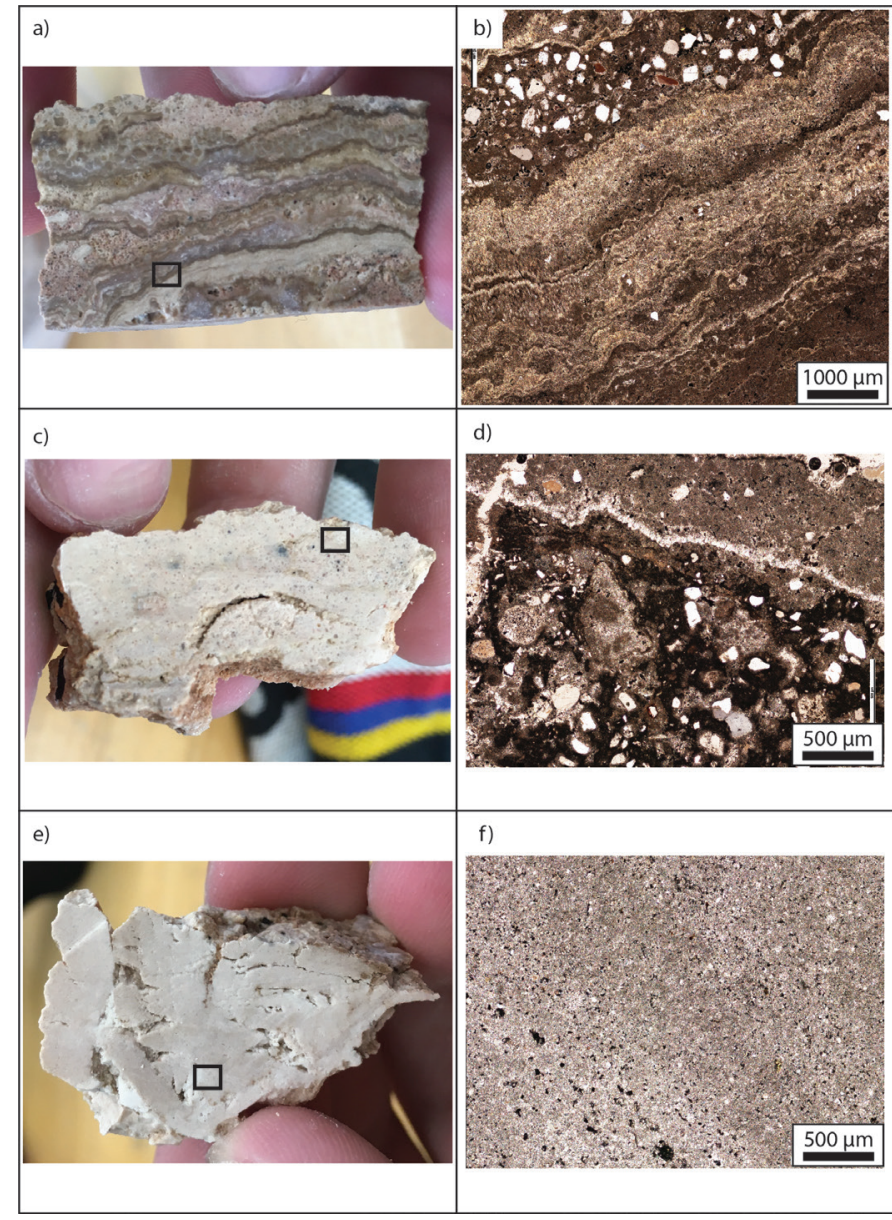

Figure 1: Three different examples of white laminae/sections. (a) Hand sample from Flat top East (FTEKCM4) collected from the top of the massive section. It shows a white section of laminae towards the bottom. This sample if oriented with the top facing upwards. (b) Thin section showing the white laminae in thin section in the SE corner. The white layer in thin section is dark brown and homogenous. (c) Hand sample from Flat top West (FTWKC3) collected from an erosional surface of the laminar cap on the top of the transitional. Few laminae are present. (d) Thin section showing the dark mass similar to b but with more quartz sand grains and more heterogeneity throughout perhaps indicating a younger age. One laminae of crystals of calcite is seen. (e) Fragment from Flat top West (FTWV2) collected from the muddy creek section b unit 2. (f) Nearly all calcite crystals. Slight banding is seen from NW to SE of picture. The alternating sections differ only by crystal size. The larger crystal sections display elongation of pore spaces.

$1 / 2$ wavelength $<$ amplitude. A broken shape is where there is a discontinuity in the laminae.

\section{RESULTS}

\section{Profile Morphology and occurrence of laminae in the field profiles}

VAll types of laminae were seen at all three sites visited (MM, FTE, and FTW) and in horizons at different depths throughout the profile. Laminae were observed in many directions, not only horizontal to the surface extending for continuous lengths of 10 s of $\mathrm{cm}$. Laminae were however found roughly horizontal to the surface either in a draping manner or in horizontal cracks consistent with Bullock et al. (1985). Additionally, six different colors of laminae were identified: white, red, dark olive gray, pale brown, pink, and light brown.

\section{Optical Microscopy}

Contacts between laminae in thin section range from very sharp $(<2 \mu \mathrm{m})$ to diffuse (color/particle size transition $>60 \mu \mathrm{m}$ wide) (Stoops, 2003; Bullock et al., 1985). Most contacts between differing laminae are pronounced and abrupt, but on some, especially the alternating pink and light brown laminae, the contact was not easily discernible in thin section. Most laminae are wavy (53.2\%), but some are irregular $(29.8 \%)$ and some are broken (14.9\%). Only $2.1 \%$ have a straight contact.

Most laminae could be traced laterally across the entire thin section (88.1\%), with a few that were only $50 \%$ traceable throughout the thin section $(9.5 \%)$. Infilled voids and cracks were prominent, recognizable due to their composition of sediments of silt/clay/sand that contrasted with the matrix and laminae, or by larger $(>50 \mu \mathrm{m})$ calcite crystals growing in radially from the void edges.

Colors distinct in hand sample remained distinct at the microscopic scale, correlating with grain size (pedogenic crystal size) and mineralogy. "White" laminae were generally comprised of very fine grained $(<50 \mu \mathrm{m})$ calcite mixed with clay and fine matrix, though sizes range from micrite $(<4 \mu \mathrm{m}$ crystals) to microsparite $(4-50 \mu \mathrm{m})$ (Bullock et al., 1985). In most samples, the white laminae fabric is homogenous and dark brown to black in thin section (Fig. 1a, b). In some cases, white layers contained quartz sand grains that were rounded to subrounded (Fig. 1c, d). In one case where the entire hand sample was white (Fig. 1e, f), the laminae within were almost entirely crystalline calcite. In this sample, weak banding was seen as a slight variation in crystal size possibly indicating different periods of growth. 
Red laminae show crenulated calcite layering rich in oxides and clays. Some laminae exhibit a convolute (Stoops et al. 2003) or irregular ( $1 / 2$ wavelength $<$ amplitude) orientation. Some red laminae are present in very distinct bands or sections where several laminae are seen to have a red tint (Fig 2a, b). These bands are often thin $(<1000 \mu \mathrm{m})$, long $(>3 \mathrm{~cm})$, and continuous across the sample. Other red laminae/ sections occur in larger swaths or areas (Fig. 2c, d). In these sections, the redness seems to be a haze over the entire area, where underlying laminae and sections are still visible with carrying degrees of light and dark red.

The dark olive gray laminae in thin section show fine to coarse interlocking sparry calcite $(10-300 \mu \mathrm{m})$ that ranges from equigranular hypidiotopic to equigranular idiotopic (Bullock et al., 1985) and fine clays. The sparry calcite crystals seem to grow in bands possibly parallel to overall laminae orientation; they also radiate perpendicularly from darker masses that are consistent with white areas in hand sample (Fig. 3a, b). Dark laminae can also form in cracks where they are made up of radiating calcite crystals (Fig. 3c, d).

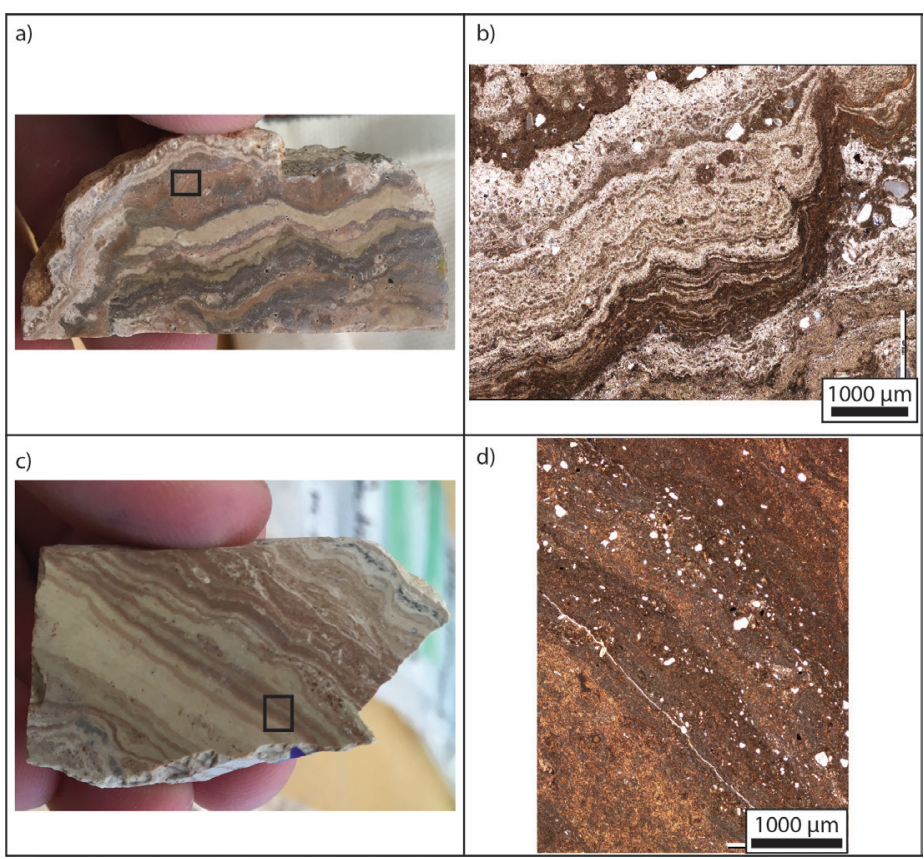

Figure 2: Two different examples of red laminae/sections. (a) Hand sample from Flat top East (FTEKCM2) collected from the upper part of the massive section. (b) Thin section showing a very distinct red laminae section. (c) Hand sample from Flat top East (FTEKCM6) collected as a grab sample(not in situ). (d) Thin section showing prominent red laminae. Redness is almost a tint or haze over entire area.

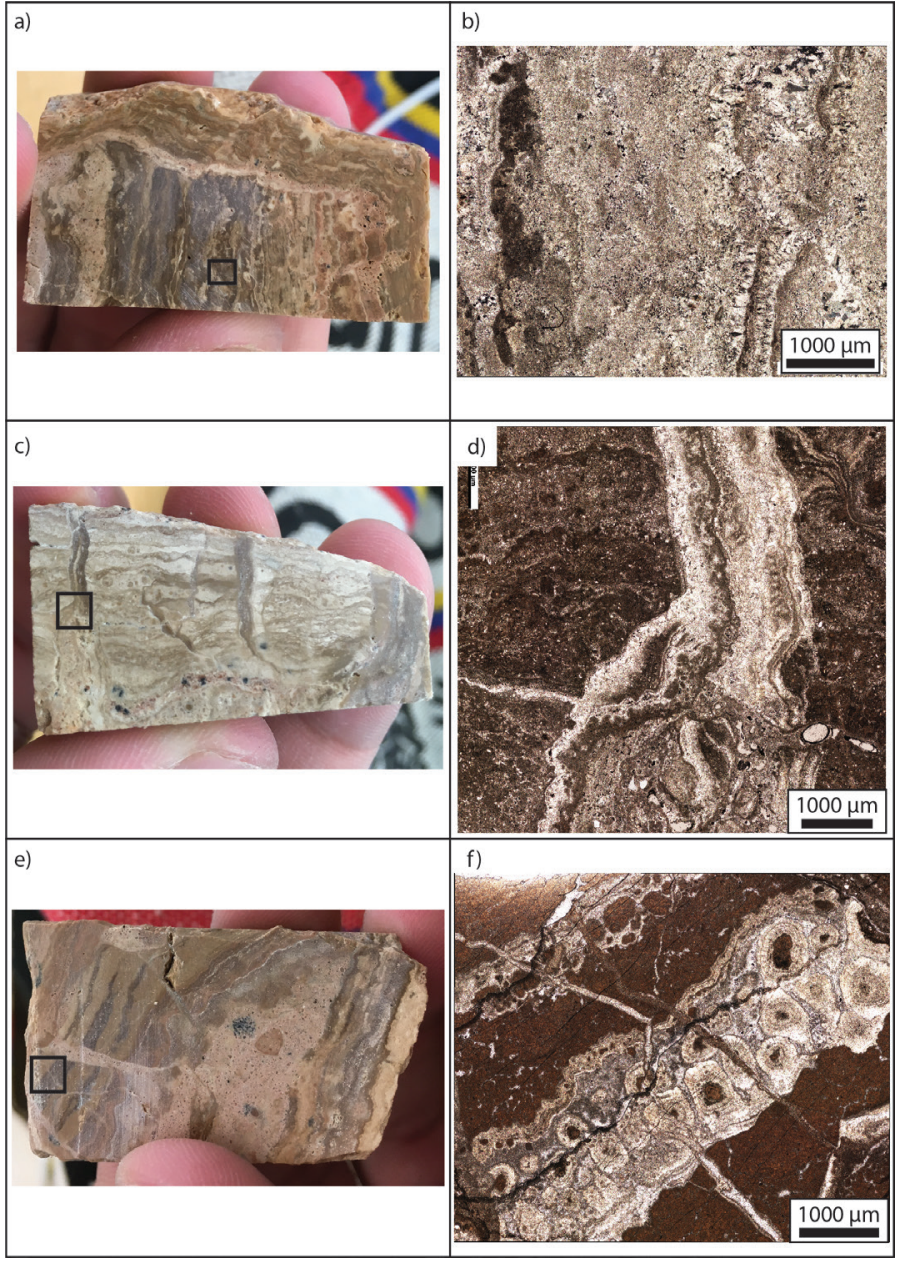

Figure 3: Three different examples of dark olive grey laminae. (a) Hand sample from Flat top East (FTEKCM1) collected from the upper middle part of the massive. (b) Thin section showing large calcite crystals. Some crystals seem to be growing off of or radiating from darker laminae segments, which are identified as white or lighter sections in hand sample. (c) Hand sample from Flat top East (FTEKCM3) collected form the upper section of the massive. (d) Thin section showing a crack filled dark laminae. The calcite crystals are radiating and forming in bands off of the darker areas which are white in hand sample. (e) Hand sample from the Riverside site at Mormon Mesa (MMRKC31L) cut with a saw and oriented. (f) Thin section showing concentric ooids with radiating calcite forming the darker laminae layer.

In some cases, dark laminae are largely comprised of numerous, adjacent ooids (concentric calcite concretions) (Fig. 3e, f). These findings, especially the ooids, corroboratereporting by Stoops et al. (2010).

The pale brown laminae are mostly comprised of densely packed, predominately phyllosilicate aggregate clusters, though some areas show loosely packed aggregates (Bullock et al., 1985). The aggregates in the pale brown laminae or sections range from being more matrix supported (Fig. 4a, b) to being more clast supported (Fig. 4c, d). In some cases, 


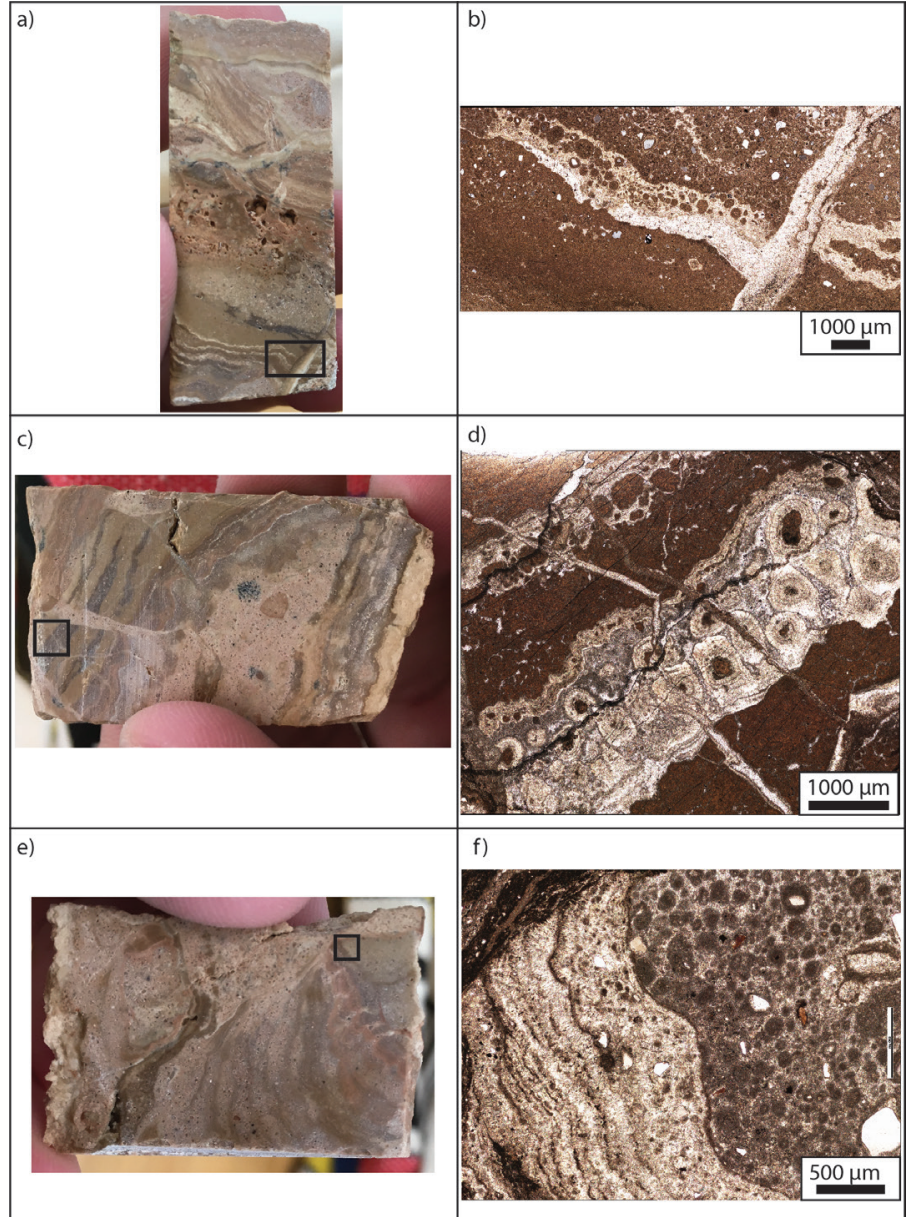

Figure 4: TThree different examples of pale brown laminael sections. (a) Hand sample from the Riverside site at Mormon Mesa (MMRKC32) cut with a saw and oriented. (b) Thin section showing aggregates clustered together in the NE part of the picture. The aggregates in the laminae are more ooid like with space and growth around them, but the aggregates above in the NE seem to be more stuck together. (c) Hand sample from Riverside site at Mormon Mesa (MMRKC31L) cut with a saw and oriented. (d) Thin section showing pale brown laminae on both sides of an ooid layer (dark olive grey laminae). Aggregates seem very together and only are barely visible in the bottom half of the picture. (e) Hand sample from Flat top West (FTWKC4) collected from the stage IV laminar cap. (f) Thin section showing the aggregate clustered together in the pale brown area.

there is almost no space between aggregates and the layer appears to be completely or nearly completely homogenous (Fig. 4e, f).

The differences in the pink and light brown laminae are difficult to see in thin section. Both are made up of mostly calcite with larger quartz grains scattered throughout in bands parallel to the laminae orientation and clays and exhibit an internal fabric of microlamination (Stoops et al. 2003). It is easier to tell them apart when they are adjacent to each other in the sample. One sample collected shows a thick section of many alternating light brown and pink laminae, which is typical (Fig. 5a, c). The thin section shows alternating layers of reddish tinted mass and layers with a higher quartz grain content. The layers with more quartz are the pink layers and the layers with more of a red hue are the light brown layers (Fig. 5b). Alternating pink and light brown laminae are very common and occur in many places throughout the Mormon Mesa and Flat Top Mesa.

\section{DISCUSSION}

\section{Interpretations of micromorphology}

The laminae orientation seems to not be solely parallel to the overall landscape of the Mormon Mesa and Flattop Mesa. This means that laminae are forming not only as a cap but throughout the massive section

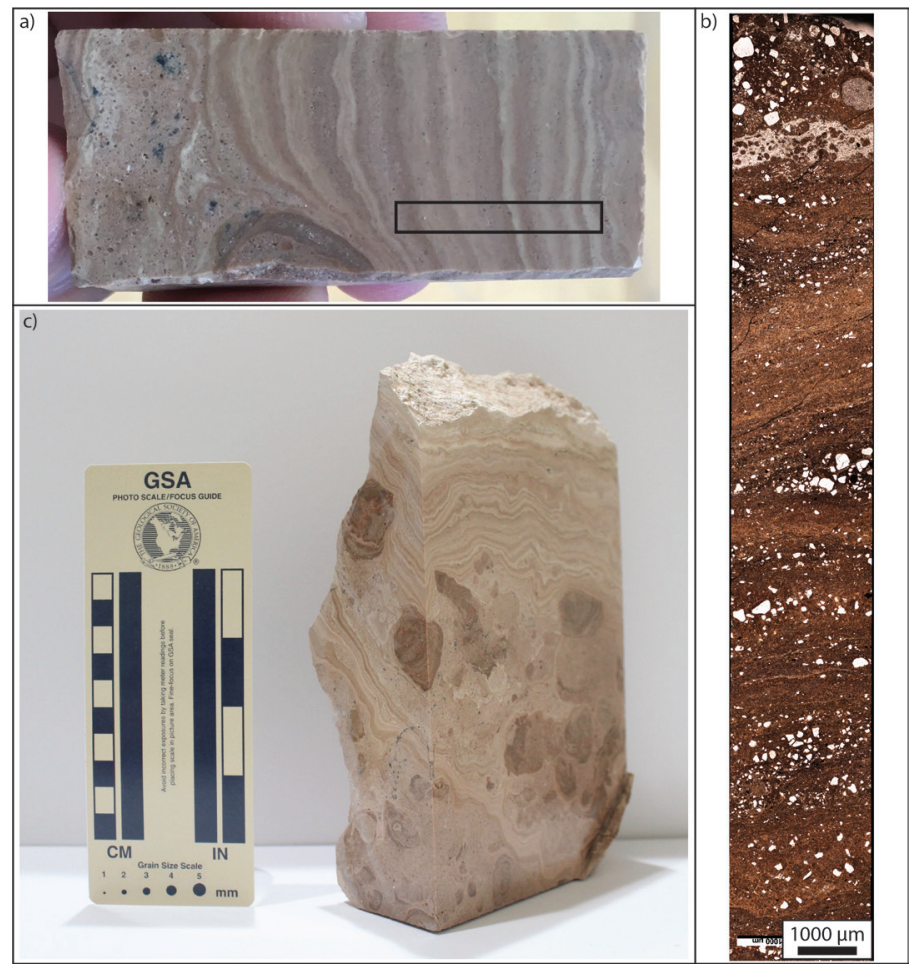

Figure 5: Examples of light brown and pink laminae. (a) Thin section billet showing where thin section picture $c$ is taken. (b) Large hand sample from the Riverside site at Mormon Mesa (MMRKCM4) cut out of the massive horizon with a saw and oriented. Large section of alternating light brown and pink laminae are seen as well as larger pisoliths. Laminae in large part is parallel to horizon. (c) thin section strip showing pink and light brown laminae. The pink, or lighter, laminae are those sections that have a higher quartz grain content. The light brown, or darker, laminae have a reddish tint and have less quarts comparatively to the pink laminae. 
filling voids and fractures/joints.

\section{Interpretations of mineralogy seen in microscope}

Some basic differences between the six main types of laminae are noted. The white laminae are usually very fine-grained sections that appear to have no crystalline structure being homogenously dark brown under the microscope. Some larger white layers could also be made up of wholly calcite crystals with banding. The red laminae appear to be oxidized and are very distinct. In some cases, there is a red haze seen in the laminae. The dark olive grey laminae are comprised of large sparry calcite crystals that are a secondary feature due to dissolution and recrystallization. These crystals radiate away usually from white laminae, or sometimes from other colors of laminae and most likely had the most time to grow. Some dark laminae could be attributed to concentric radially growing ooids. The pale brown laminae are almost entirely made up of small aggregates that can range from slight matrix supported to clast supported. Sometimes the aggregates will be so smashed up against each other that it is very difficult to point out the individual aggregates. The pink and light brown laminae are very similar in composition, and almost always alternate between one another. The difference is that the pink laminae and sections seem to have a higher quartz or sand grain content as opposed to the light brown laminae. Both seem to have a red hue under the microscope.

\section{CONCLUSIONS}

Several conclusions can be drawn. First, top-bottom indicators do exist, at least as a rule, though some laminae do not form from the top down. There are too many examples of laminae forming in cracks and voids that appear similar in shape and size to vertical forming laminae. Second, the wide variety of laminae colors represent differences in crystal size, detrital grain content, and mineralogy. The differences are seen in Figures 1-5. Third, laminae do form differently when in cracks and fractures than those seen forming in soil matrix. The laminae in cracks and voids seem to be either infill of aggregates/clay/sand, or growth of sparry calcite crystals. This study fills a gap in existing models of (petro)calcic horizon and profile development and any insights gained from Mormon Mesa petrocalcic horizons can hopefully be applied to other arid soils and paleosols worldwide.

\section{ACKNOWLEDGEMENTS}

This material is based upon work supported by the Keck Geology Consortium and the National Science Foundation under Grant No. 1659322. I thank Colin Robins, who lead our project, and team members Ethan Conley, India Futterman, and Penelope Vorster. Bob Gaines of Pomona College Geology and Kyle McCarty have lent a tremendous hand in guidance and lab technical work.

\section{REFERENCES}

Alonso-Zarza, A.M., Tanner, L.H., 2010. Paleoenvironmental record and applications of calcretes and palustrine carbonates. Geologic Society of America Special Paper 416, 1-15.

Arakel, A. V. 1982. Genesis of calcrete in Quaternary soil profiles, Hutt and Leeman Lagoons, Western Australia. Journal of Sedimentary Petrology, 52(1), 109-125.

Bigham, J.M., Jaynes, W.F., Allen, B.L. 1980. Pedogenic Degradation of Sepiolite and Palygorskite on the Texas High Plains. Soil Science Society of America Journal 44 (1) 159167.

Brock, A.L. and Buck, B.J., 2009. Polygenetic development of the Mormon Mesa, NV petrocalcic horizons: Geomorphic and paleoenvironmental interpretations. Catena 77 : 65-75.

Bullock, P., Fedoroff, N., Jongerius, A., Stoops, G., Tursina, T. 1985. Handbook for Soil Thin Section Description. Waine Research.

Gile, L.H., Peterson, F.F. and Grossman, R.B., 1966. Morphological and genetic sequences of carbonate accumulation in desert soils. Soil Science 101(5): 347-360.

Russell, D., Hudnall, W.H., Allen, B.L. 2010. 
Micromorphology investigation of sepiolite bearing petrocalcic horizons formed from lacustrine sediments on the southern high planes of Texas and New Mexico. Australian Clay Minerals Conference, 21, 43-46.

Levine, S.J., Hendricks, D.M. 1990. Carbonate forms in Residual Horizons of Limestone Derived Soils in Northern Arizona. Developments on Soil Science, Volume 19, 373-380.

Machette, M.N., 1985. Calcic soils of the southwestern United States. In: Weide, D.L. Soils and Quaternary Geology of the southwestern United States. Geologic society of America Special Paper 203: 1-21.

Monger, H. C. and L. A. Daugherty, 1991. Neoformation of Palygorskite in Southern New Mexico Aridisols. Soil Science Society of America Journal. 55:1646-1650.

Robins, C.R., Deurlington, A., Buck, B.J., and Brock-Hon, A.L., 2015. Micromorphology and formation of pedogenic ooids in calcic soils and petrocalcic horizons. Geoderma 251-252: 10-23.

Schoeneberger, P.J., Wysocki, D.A., Benham, E.C., Broderson, W.D., and Soil Survey Staff, 2013. Field book for describing and sampling soils, Version 3.0. Lincoln: Natural Resources Conservation Service, National Soil Survey Center.

Soil Survey Staff, 2014. Keys to Soil Taxonomy, 12th ed. USDA-Natural Resources Conservation Service, Washington, DC.

Stoops, Georges, et al. 2003 Guidelines for Analysis and Description of Soil and Regolith Thin Sections. Soil Science Society of America.

Stoops, Georges, et al. Interpretation of Micromorphological Features of Soils and Regoliths. Elsevier, 2010.
Vanden Heuvel, R. C., 1966. The Occurrence of Sepiolite and Attapulgite in the Calcareous Zone of a Soil Near Las Cruces, New Mexico. Clays and Clay Minerals. 13:193-207. 